\title{
Brassidic Acid
}

National Cancer Institute

\section{Source}

National Cancer Institute. Brassidic Acid. NCI Thesaurus. Code C68326.

A monounsaturated very long-chain fatty acid with a 22-carbon backbone and a single double bond originating from the 9th position from the methyl end, with the double bond in the trans- configuration. 